\title{
APPLICATION OF PHOTOGRAMMETRIC TECHNIQUES IN PALAEOODONTOLOGICAL STUDIES TROUGH AUTOMATED DIGITAL SHAPE ANALYSIS OF HUMAN TEETH
}

\author{
A.V. Gaboutchian ${ }^{1 *}$ V. A. Knyaz ${ }^{2,3}$, N.A. Leybova ${ }^{4}$, G. Petrosyan ${ }^{5}$, H. Simonyan ${ }^{6}$, S.V. Vasilyev ${ }^{4}$ \\ ${ }^{1}$ Moscow State Medical-Stomatological University, Moscow, Russia - armengaboutchian@ mail.ru \\ ${ }^{2}$ State Research Institute of Aviation System (GosNIIAS), 125319 Moscow, Russia - knyaz@gosniias.ru \\ ${ }^{3}$ Moscow Institute of Physics and Technology (MIPT), Russia \\ ${ }^{4}$ Institute of Ethnology and Anthropology RAS, Moscow, Russia - nsuvorova@mail.ru \\ 5 International Scientific-Educational Centre of NAS RA, Yerevan, Armenia - petrosyan_gohar@list.ru \\ ${ }^{6}$ Scientific Research Centre of the Historical and Cultural Heritage, Yerevan, Armenia - haksimon@ gmail.com
}

\section{Commission II, WG II/10}

KEY WORDS: Photogrammetry, Odontology, Automated Digital Odontometry, Anthropology, Sungir, Nerqin Naver, Sviyazhsk, Tooth 3D shape analysis

\begin{abstract}
:
Odontological studies, which constitute a considerable part of anthropological research, have been predominantly based on visual, or odontoscopic, examination of teeth. The most studied parts are coronal parts of teeth in terms of their relief features, and, in reference to the current study, tooth cusp relief eminence, sharpness of cusp tips and degree of tooth outer slope inclination are of interest. Traditional odontological methods, in addition to visual, suggest measurement techniques for coronal parts in mesio-distal and vestibular-oral dimensions, which actually do not possess methodological potential for reasonable angular measurements. However, the suggested automated digital odontometric method, being largely based on photogrammetric techniques applied to 3D images of teeth, has showed its usability for such assessments. Tooth shape analysis is provided through software, being permanently elaborated in terms of automation degree for measurement objectivity and precision increase, as well as in expansions of parameters variety. Odontological samples from Upper Palaeolithic archaeological site of Sungir are picked for measurements in the current study due to their presumably archaic relief of molars, described for this unique finding by prominent odontologist A.A Zubov. This research includes comparisons with odontological material, which historically refers to significantly later periods (Early Bronze and Modern Era). The applied digital method has showed its effectiveness in estimation of parameters of demand in anthropological studies, and evaluations of visual studies and measurements are suggested in the article.
\end{abstract}

\section{INTRODUCTION}

Methods of odontometric angular measurements are not described as established techniques, though it is possible to find some data referring to cups relief features in literature (Kraus et al., 1980). Thus we can presume that such records are based on approximate estimates, more likely visually determined than measured. Among numerous parameters, measured or calculated by means of automated digital odontometry, angular and inclination depicting parameters are currently of interest. The suggested measurement technique is based on clearly defined measurement landmarks on contours of teeth (Figure 1), if compared to other techniques (Dental (Tooth) Anatomy; Figure 2-18). Photogrammetric methods and appropriate 3D image processing software enhance measurement precision, objectivity and applicability through automated landmark detection.

It should be mentioned that measured angles of cusp slopes inclination do not fully depict the observers visual impression, referring to cusp sharpness as, due to dental morphology, cusp slopes are not flat. Their outer cusp slopes are always convex; curvatures of inner slopes contours are more complex and variable, which impairs assessments. Thus in line with measured parameters, calculated coefficients are suggested for more comprehensive odon-

\footnotetext{
${ }^{*}$ Corresponding author
}

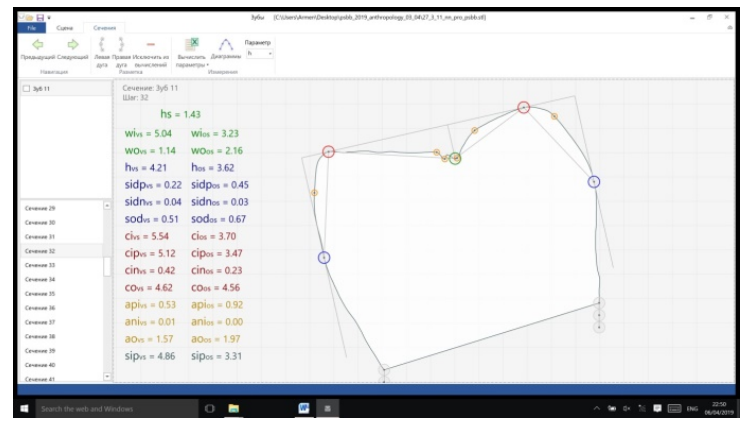

Figure 1. Tooth section with odontometric landmarks

tometrical descriptions of dental morphological features; among such are tooth contour lengths, their eminences, inclination angles and others.

The discussed above morphological features of tooth crowns are of high exploratory significance in odontological research as they can serve for estimation of epochal and territorial variability in anthropology. This is mainly due to studies of prominent Soviet and Russian odontologist Alexander A. Zubov, who had described internally inclined cusp slopes, giving visual impression of sharpened cusps and prominent occlusal relief, as an archaic 
feature. However, this hypothesis has not been confirmed yet, and we are seeking in the current study for objective data verifying the assumption through measurements and comparisons on samples of various dating: Upper Palaeolithic Sungir, Early Bronze Nerqin Naver and Modern Era Sviyazhsk.

In view of the above, measurement objectivity plays an important role in odontometric studies. For this reason software development advances towards enhancement of automation degree. Similar to traditional, performed manually, automated odontometric techniques depend on correct orientation of the measured tooth (as teeth or their coronal parts have complex shape). Thus, odontomtric data presented in the article is obtained after automated calibration process preceding direct measurements.

Presenting archaeological sites of the studied findings, we should start with Sungir, which materials have become the principal part for the current study. One of the northernmost Upper Palaeolithic archaeological sites on Russian Plain was presented to reading audience for the first time in 1959 (Bader, 1959). Since that a significant number of archaeological and anthropological studies have been held, including recent genetic.

The site is located on the left riverbank of Klyazma on 5-8 meter height above the water lever. The cultural layer of the site is integrated into clay loam mantle covering Dneprovian (also known as Wolstonian) moraine. Geological age dating of the site has been estimated between Mikulin (or Eemian) interglacial and Ostashkovski (or late Valday, or Wisconsin) glacial periods (Bader et al., 1961).

At the moment a series of varying dating exists which are based on mammoth, horse and reindeer bone collagen analysis (Sulerzhitsky et al., 2004). The major part of dating records refer to period between 28800240 (GIN-90) and 26300300 (GIN-9034) years and this corresponds to the period of high level of activity at the settlement. However dating of burials shows poor coherence with cultural layer dating, thus analyses at AMS GeoGenetics laboratory (Copenhagen, Denmark) have showed 34000 dating (Sikora et al., 2017).

The grave $\mathrm{Nr} 1$ contained the skeleton of an elderly man, whose odontological samples were not studied currently. The grave $\mathrm{Nr}$ 2, containing remains of two children put head-to-head (Figure 2), was distinguished from the other by its unprecedented riches. The Southern, or C2, burial, was oriented to the NorthNorth-East by its head direction, as opposed to the Northern (C3), oriented to the SouthSouth-West. Both bodies were put stretched on their backs with hands folded on pubic area. The interment was simultaneous as large spears made of mammoth tusks occupied the both buried spaces. One of the main characteristic features of the burial implements are two long spears $(2.42 \mathrm{~m}$ and $1.66 \mathrm{~m})$ and multiple darts, as well as a flat necklace, a large bone sculpture of a mammoth (C2) and thousands of beads along bodies and on the skulls. Finding of two distal phalanx bones of cave lion or panther in the burial are of interest as well. Anthropologists and geneticists present evidence of kinship between the children (Vasilyev, 2000; Martin et al., 2017).

The majority of the anthropologists interpret Sunghir findings in terms of possible miscegenation of H. Sapiens with H. Neanderthalensis, or stages-of-man transformation, as well as early intra-species differentiations of H. Sapiens. Though nothing contradicts the possibility of co-habitation of Sapiental and Neanderthal forms on one territory, the transformation of Naenderthals

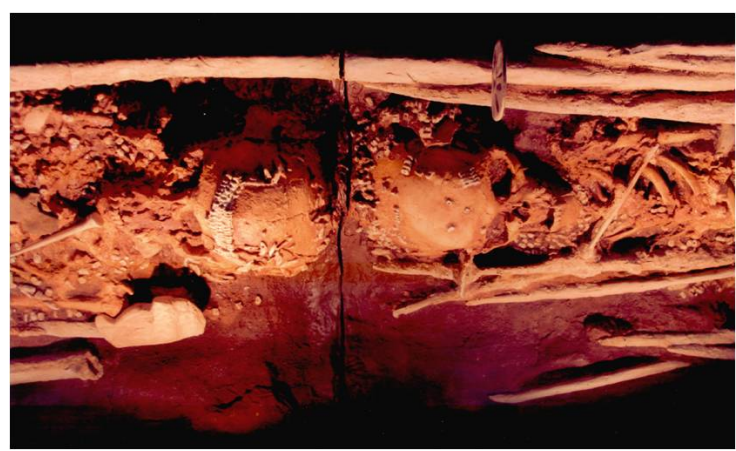

Figure 2. Sungir $\mathrm{C} 2$ and $\mathrm{C} 3$ individuals

into early Sapiental forms should have required so significant restructuring of growth gradient system and correlations of genetic complexes, which is hardly possible without organism viability loss (Bunak and Gerasimova, 1984). Ideas of specificity of neanderthal and sapiental forms as species and their possible miscegenation on early stages of development on subspecies level for maternal species of Homo heidelbergensis have been repeatedly expressed by scientists of Soviet and Russian national school (Vasilyev et al, 2017)

Search of new taxonomical determinants having group and intergroup defining features preserves its relevance in odontology. Thus a characteristic morphology of upper permanent molars had been described for individual C2 from Sunghir as sharp and high cusp tips having slight inner inclination (Zubov, 2000; p.262). Alexand A. Zubov presumed that this feature might represent an archaic aspect in general odontological description of $\mathrm{C} 2$. However assessment of cusp inclination on palaeoanthropological material is difficult due to usually severe tooth attrition. From this point of view teeth of juveniles from world-renowned Upper Palaeolithic Sunghir are an extremely rare exception of high value; they are remarkably preserved and their permanent occlusal surfaces demonstrate insignificant degree of attrition. The comprehensive morphological odontological study of $\mathrm{C} 2$ and $\mathrm{C} 3$ have revealed the following features: minor expression of incisor shovelling and Carabelli cusp, four-cusped lower second molars; absence of trigonid distal ridge, sixth cusp, inter-root enamel pearls and protostylid; minor expression of deflecting wrinkle of metaconid. A range of other features, which have been described, can be referred to archaic: hypermacrodontism, reduction of upper molar metaconid coinciding with large hypoconid, molarasation of lower premolars and others (Zubov, 2000).

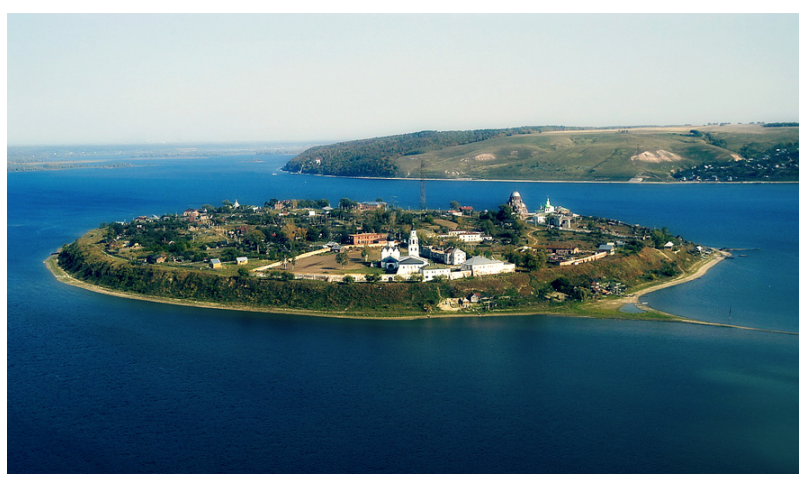

Figure 3. Sviyazhsk, birdseye view

The current study is aimed to go beyond visual odontological analysis and to conduct measurements on the tooth which was 
the first to be described by Alexandr A. Zubov in terms of prominent central inclination of molar cusps. Samples for comparisons were picked from anthropological findings of Orthodox necropolis from the territory of Sviyazhsk (XVII-XIX centures) - fortress on island near city of Kazan (Figure 3), as well as odontological samples from Nerqin Naver, which have been subjected to a number of our previous studies. Reminding our reader about this Early Bronze archaeological site located in region of Aragatzotn (Republic of Armenia), which represents a burial complex covering an area of 40 hectares. The studied samples are from burials $\mathrm{Nr} 1$ and 3 dating to XXIV-XVIII centuries BC.
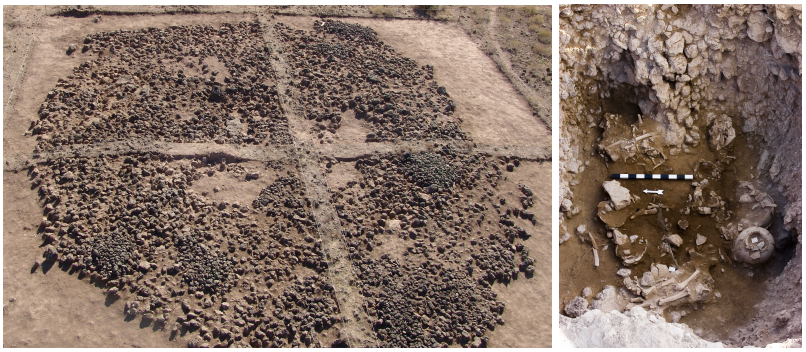

Figure 4. Burial Nr 3 of Nerqin Naver before and during excavations

Their 3D images, obtained and measurement earlier were involved in comparative part of testing changes in automated digital odontometric method.

\section{RELATED WORK}

Potential for application of digital imaging techniques in palaeoanthropological studies has started to develop with the advent of the first systems providing appropriate data (Hounseld, 1973). Further development and increasing availability of such systems has led to increase of possible applications and related products. The feasibility of studying 3D models rather than real objects creates conditions for preserving high value anthropological material. Another noticeable advantage of such techniques is in repeatability of studies and possibility of implying different methods of research. Thus computed tomography as one of methods related to 3D image generation and analysis has its applications in palaeoanthropology (Uldin, 2017) and studied on anthropological samples in terms of its tooth scanning precision (Al-Rawi B., 2010). Another method providing accurate quantitative related to tooth coronal part morphogenesis is micro-computed tomography (Smith et al., 2007).

However, natural tooth scanning, either separately or within dental arches integrated into skull bones, intraoral cameras are optimal in use due to optical characteristics of tooth tissues, which especially refers to the enamel coating covering coronal parts of teeth (Mitchell and Chadwick, 2008). Though such scanners do not provide precision for larger scale objects (such as skulls), they demonstrate acceptable precision for obtaining tooth 3D models (Jacob et al., 2015) and are definitely preferable for unique anthropological material scanning because of their mobility and non-invasive handling. Various types of measurements are conducted on digital images.

Thus landmark points obtained from 3D models (Richtsmeier et al., 2002) are used for statistical analysis (Sokal and Rohlf, 1995) using methods, such as geometric morphometrics (Bookstein, 1991). There are examples of combination of virtual reconstruction and geometric morphometrics implementation in studies of skeletal bones (Milella et al., 2014) or teeth (Gomez-Robles et al., 2007) in palaeopathological research. Tooth crown morphology has been subjected to studies using high precision 3D models (Gaboutchian et al., 2017) through evaluation of newly introduced morphological characteristics referring to tooth relief and its changes determined by functional wear during lifetime. Such odontometric assessments are held in line with traditionally used visual descriptions of dental morphology, as finding from the Es-Skhul Cave, clearly related to the current study due to estimated centrally inclined molar cusps on mandible of child (Khaldeeva et al., 2010; page 73). Lingual inclination of lower first molar vestibular cusp tips was noted as a definitely archaic feature.

\section{METHODS}

We are not going to focus on detailed description of automated digital odontometry as it has been presented in our earlier published works, including development of approaches to measurements of inclination of inner and outer tooth cusp slopes on human premolars and molars (Gaboutchian et al, 2017). Among angular parameters cusp slope inclination angles, inner and outer, are measured, as well as convergence angle of inner slopes of cusps and convergence angles of inner and outer slopes of cusp. It should be mentioned that according to the suggested technique, the above-mentioned angular parameters are not actually measured, they are calculated as tangents. Data for calculation derives generally from linear measurements of cusps and their slopes in vestibular-oral and vertical dimensions, performed on contours of teeth obtained odontotomically (Figure 5). Parameters referring to curved contours of teeth (Figure 6), as well as combinations of parameters as coefficients, have formed broad range data relating to cusp morphology as well.



Figure 5. Linear parameters measured on contours of teeth for further calculations

A significant factor having considerable impact on objectivity and precision of studies, as well as influencing on choice of measurement method, is automation of measurements, which has reached a higher degree, if compared to previous software versions. It is predominantly based on pre-measurement calibration stage through radial sectioning of teeth (Figure 7). 




Figure 6. Tooth contour measurements
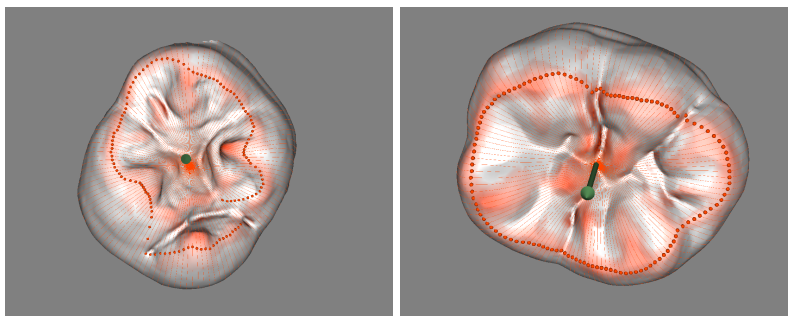

Figure 7. Linear parameters measured on contours of teeth for further calculations

Odontological samples were taken from Upper Palaeolithic archaeological site of Sungir (Sunghir), which is well-known significantly for its burials, dated to approximately 30th millennia BC. Two of three bodies (Sungir-2 and Sungir-3) belong to juveniles and morphology of their teeth, according to observations, corresponds to archaic taxonomical feature of high degree of cusp slope internal inclination (described as a hypothesis, estimated odontoscopically). In order to conduct measurement, 3D images of studied odontological samples dental arches and separate teeth (Figure 5) were obtained by intraoral scanner 3shape, TRIOS (courtesy of DDA, Russia). The scanning method and device were chosen to reduce damage risks and to avoid invasive procedures while studying the unique findings. Two teeth were picked from sungirian $\mathrm{C} 2$ individual: upper molar (2.7) with almost no attrition (the one which had been described as morphologically archaic) and, having early signs of attrition, lower molar (3.6).
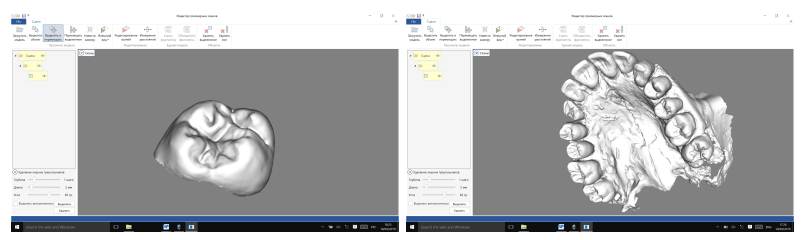

Figure 8. Upper dental arch scan and 2.7 tooth extracted from the image; individual C2

The objectives of research consider comparative measurements on teeth with different/opposite to above-mentioned features and dating. Therefore samples were chosen from the database (Knyaz V., 2018) formed of teeth images various in dating and features (territory, age, tooth type, scanning device and etc.). Thus upper molar (2.7) from Nerqin Naver burial 3 was picked, being the most appropriate (despite attrition on its oral cusp) to be compared with 2.7,C2. Lower 4.6 with almost no attrition, taken from Sviyazhsk anthropological samples, was measured to be compared with 3.6,C2 from Sunghir.

Measurements included slope (both, inner and outer) inclinations referring to vestibular and oral cusps; cusp slope convergence, or cusp tip, angle. Angular parameters are presented in degrees. Cusp slope contour lengths are measured as well. All parameters are average, not maximal as traditional odontometric techniques suggest, and thus refer to teeth as a whole. Maximal parameters and their locations are not studied in the current research. However some newly suggested parameters are introduced; they refer to tilts of occlusal and equator extreme value points connecting planes (Figure 9).

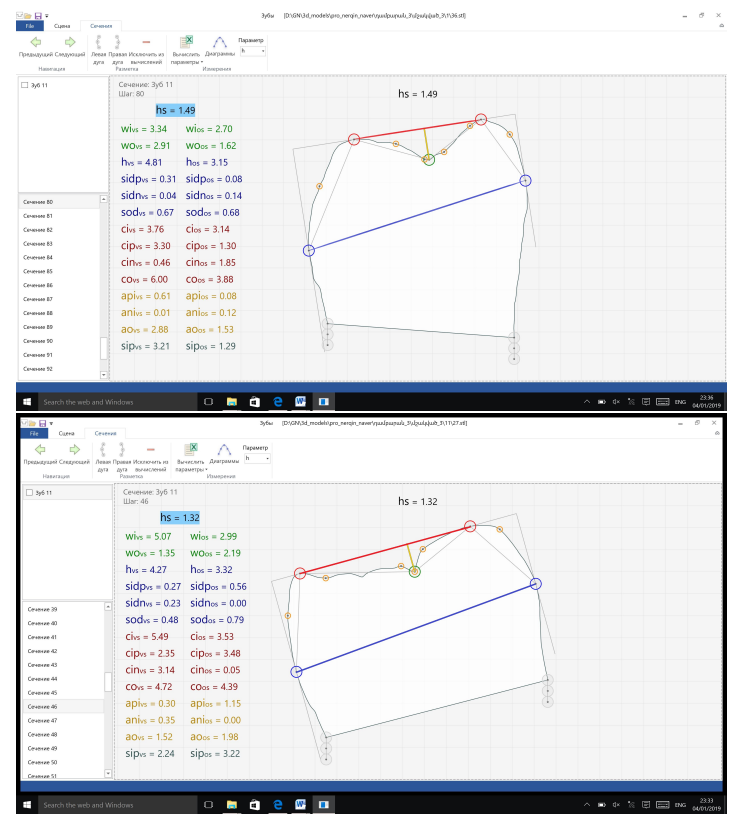

Figure 9. Variety in tilts of planes on contours of teeth

\section{RESULTS AND DISCUSSION}

The existing situation in traditional manual anthropological odontometry might give the impression that visual, real object or $3 \mathrm{D}$ image, analyses are the best suited ways for estimating tooth occlusal relief features. However, precise data obtained by application of automated digital odontometry, clarifies morphological characteristics of human teeth through objective parameters. Angular and linear parameters are presented for upper left second molars 2.7,C2 and 2.7,HH (Table 1).

Table 2 shows angular and linear parameters of lower right and left first molars 3.6,C2 and 4.6,CB7.

Angular parameters are clearly shown on Figure 10.

Outer cusp slope inclination measurements on 2.7,C2 have showed noticeably higher values in comparison to $2.7, \mathrm{HH}$. Despite the fact that inner slope inclinations differ (the angle is wider on 2.7,HH which is results from attrition, both teeth show similar patterns: angles are wider on vestibular cusps. However cusp tip angle parameters markedly differ on the compared teeth: primarily by their values as well as by predominant cusp location (vestibular or oral). Nonetheless 2.7,C2 has sharp ended vestibular and oral cusps and more expressed inner inclination of vestibular cusps if compared to $2.7, \mathrm{HH}$ (vestibular cusps can be compared directly on both teeth as their outer slopes are not affected by attrition). The described morphological feature of curved and inwards bent cusps is confirmed by contour length parameters, markedly higher on sungirian tooth on both, inner and outer, slopes of vestibular cusps. 


\begin{tabular}{|c|c|c|}
\hline Parameter & \multicolumn{2}{|c|}{ Upper teeth } \\
\hline & $2.7, C 2$ & $2.7, \mathrm{HH}$ \\
\hline \multicolumn{3}{|c|}{ Outer slopes inclination (vestibular \& oral } \\
\hline$\beta_{v s},{ }^{\circ}$ & 28.581 & 21.940 \\
\hline$\beta_{o s},{ }^{\circ}$ & 32.351 & 35.678 \\
\hline \multicolumn{3}{|c|}{ Inner slopes inclination (vestibular \& oral) } \\
\hline$\alpha_{v s},{ }^{\circ}$ & 57.531 & 75.948 \\
\hline$\alpha_{o s},{ }^{\circ}$ & 51.059 & 69.584 \\
\hline \multicolumn{3}{|c|}{ Cusp tip angle (vestibular \& oral) } \\
\hline$\gamma_{v s},^{\circ}$ & 86.112 & 97.887 \\
\hline$\gamma_{o s},{ }^{\circ}$ & 83.415 & 105.263 \\
\hline \multicolumn{3}{|c|}{ Vestibular cusp contour length (inner \& oute } \\
\hline$C_{i v}, m m$ & 4.479 & 3.054 \\
\hline$C_{o v}, m m$ & 6.744 & 3.526 \\
\hline
\end{tabular}

Table 1. Odontometric parameters for upper teeth

\begin{tabular}{|c|c|c|}
\hline Parameter & \multicolumn{2}{|c|}{ Lower teeth } \\
\hline & $3.6, C 2$ & $4.6, C B$ \\
\hline \multicolumn{3}{|c|}{ Outer slopes inclination (vestibular \& oral) } \\
\hline$\beta_{v s}{ }^{\circ}$ & 36.286 & 25.551 \\
\hline$\beta_{o s},{ }^{\circ}$ & 25.424 & 29.172 \\
\hline \multicolumn{3}{|c|}{ Inner slopes inclination (vestibular \& oral) } \\
\hline$\alpha_{v s},{ }^{\circ}$ & 67.497 & 60.136 \\
\hline$\alpha_{o s}$, & 67.537 & 60.781 \\
\hline \multicolumn{3}{|c|}{ Cusp tip angle (vestibular \& oral) } \\
\hline$\gamma_{v s},{ }^{\circ}$ & 103.783 & 85.686 \\
\hline$\gamma_{o s}{ }^{\circ}$ & 92.961 & 89.953 \\
\hline \multicolumn{3}{|c|}{ Vestibular cusp contour length (inner \& outer) } \\
\hline$C_{i v}, m m$ & 3.506 & 3.082 \\
\hline$C_{o v}, m m$ & 5.965 & 4.534 \\
\hline
\end{tabular}

Table 2. Odontometric parameters for lower teeth

Due to masticatory system structure vestibular cusps of upper teeth are analogous to oral cusps on lower; as well as upper oral cusps should be compared to lower vestibular. And thus upper and lower studied teeth show similarity in our study in terms of outer slope inclination and cusp tip angle parameters. Though the mentioned odontometric parameters characteristic for upper tooth from Palaeolithic ages correspond to relatively modern lower tooth from Sviyazhsk. And sungirian lower molar resembles by its parameters upper tooth from Bronze Age Nerqin Naver. Thus we can not confirm by currently presented measurements the archaism of the described morphology, although it is impossible to exclude entirely random expression of archaic features on modern teeth.

Nevertheless there is a significant factor impacting tooth morphology regardless of sample dating: it is attrition, and its influence more likely affects comparison of measurement results on upper and lower teeth. Returning to lower teeth measurements, we would like to pay attention to interesting similarity of inner

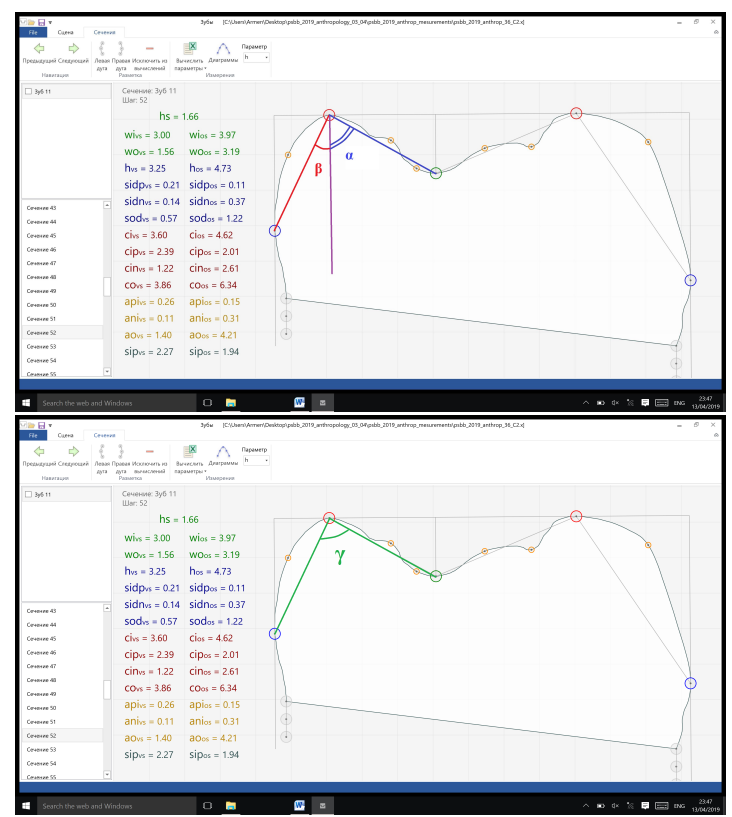

Figure 10. Cusp slope inclination and cusp tip angles on tooth contour

slope inclination angles on 3.6,C2 and 4.6,CB.

\section{CONCLUSION}

The conducted odontometric study have showed that photogrammetric techniques provide essential potential for development of anthropological and palaeoanthropological studies in terms of data capturing, image processing, and data analysis. The current research utilizing automated digital odontometry has confirmed visual dental morphology descriptions of Upper Palaeolithic findings. Though more profound studies, involving other odontometric parameters, and statistically significant sample quantity and variety is required for referring the discovered features to typically archaic.

Thus the presented multidisciplinary cooperation based on photogrammetric techniques, reveals the potential of automated digital odontometry as objective research method for unresolved issues in odontology, giving an impetus for its further development in anthropological studies.

\section{ACKNOWLEDGEMENTS}

The work was performed with the support by Grant 17-29-04509 of Russian Foundation for Basic Research (RFBR).

\section{REFERENCES}

Al-Rawi B., Hassan B., Vandenberge B., Jacobs R. 2010. Accuracy assessment of three-dimensional surface reconstructions of teeth from Cone Beam Computed Tomography scans. Journal of Oral Rehabilitation. Vol. 37(02):352-8. doi: 10.1111/j.13652842.2010.02065.x

Bader, 1959. Bader O.N. Paleoliticheskaya stoyanka na $r$. Klyazme, In: Sovetskaya Arkheologiya, No. 1.pp 144-155

Bader et al., 1961, Bader O.N., Gromov I.S., Sukachev V.I. Verkhnepaleoliticheskaya stoyanka Sungir In: Voprosy geologii 
antropogena, K VI kongressu INQUA v Varshave, 1961 g., Academy of Sciences of USSR, Moscow

Bookstein, 1991. Bookstein F.L., 1991. Morphometric Tools for Landmark Data: Geometry and Biology. Cambridge University Press. 435 pages

Bunak and Gerasimova, 1984. Bunak V.V., Gerasimova M.M. 1984, Verkhnepaleoliticheskiy cherep Sungir 1 i ego mesto v ryadu drugikh verkhnepaleoliticheskikh cherepov, In: Sungir. Antropologicheskoe issledovanie, Nauka, Moscow, pp 14-99

Gaboutchian et al., 2017. A. Gaboutchian, V. Knyaz, N. A. Leybova. Measurements of cuspal slope inclination angles in palaeoanthropological applications. Int. Arch. Photogramm. Remote Sens. Spatial Inf. Sci., XLII-2, 339-345, 2018. https://doi.org/10.5194/isprs-archives-XLII-2-W4-185-2017

Gaboutchian et al., 2018. A. Gaboutchian, H. Simonyan, V. Knyaz, G. Petrosyan, L. Ter-Vardanyan, N. A. Leybova, and S. V. Apresyan. Automated Shape Analysis Of Teeth From The Archaelogical Site Of Nerqin Naver Int. Arch. Photogramm. Remote Sens. Spatial Inf. Sci., XLII-2, 339-345, 2018. https://doi.org/10.5194/isprs-archives-XLII-2-339-2018

Gomez-Robles et al., 2007. A. Gomez-Robles, M. MartinnTorres, J-M. Bermdez de Castro, A. Margvelashvili, M. Bastir, J.L. Arsuaga, A. Prez-Prez, F. Estebaranz-Snchez, L. Martnez Martnez,. (2007). A geometric morphometric analysis of hominin upper first molar. Journal of human evolution. 53. 272-85. 10.1016/j.jhevol.2007.02.002.

Dental (Tooth) Anatomy. Access: http://www.homesteadschools. com/dental/courses/anatomy/Chapter2.htm

Knyaz V., Gaboutchian A. and Leibova N. 3D models of paleoanthropological odontological objects TOM-PO. Database. Access: http://www1.fips.ru/fips_servl/fips_servlet?DB=DB\&rn= 4726\&DocNumber $=2018621315 \&$ TypeFile $=\mathrm{html}, 2018$

Hounsfield, 1973. Hounseld, G.N., 1973. Computerized transverse axial scanning (tomography): Part 1. description of system. The British Journal of Radiology 46(552), pp. 10161022. PMID: 4757352.

Jacob et al., 2015. Jacob H.B., Wyatt G.D., Buschang P.H. Reliability and validity of intraoral and extraoral scanners. Progress in Orthodontics (2015) 16:38 doi: 10.1186/s40510-015-0108-7

Khaldeyeva et al., 2010. Khaldeyeva N.I., Kharlamova N.V., Zubov A.A. Comparative odontological study if classical Western-European Neanderthals in: Vestnik Antropologii, Vol 18, 2010, pp 60-87.

Kraus et al., 1980. Kraus, B.S., Jordan, E., Abrams, L.R., 1980. Dental anatomy and occlusion : a study of the masticatory system. 11th printing edition. Williams \& Wilkins, 317 pages. Milella, 2015. Milella, M., Zollikofer, C. P., de Len, M. S. P., 2015. Virtual reconstruction and geometric morphometrics as tools for paleopathology: A new approach to study rare developmental disorders of the skeleton. The Anatomical Record, 298(2), pp. 335345 .

Mitchell and Chadwick, 2008. Mitchell, H.L., Chadwick, R.G., 2008. Challenges of photogrammetric intra-oral tooth measurement. The International Archives of the Photogrammetry, Remote Sensing and Spatial Information Sciences. Vol. XXXVII. Part B5. Beijing

Richtsmeier, 2002. Richtsmeier, J. T., Deleon, V. B., Lele, S. R., 2002. The promise of geometric morphometrics. American Journal of Physical Anthropology 119(35), pp. 6391.

Sikora et al., 2017. Sikora M., Seguin-Orlando A., Sousa V.C., Albrechtsen A., Korneliussen T., Ko A., Rasmussen S., Dupanloup I., Nigst P.R., Bosch M.D., Renaud G., Allentoft M.E., Margaryan A., Vasilyev S.V., Veselovskaya E.V., Borutskaya S.B., Deviese T., Comeskey D., Higham T., Manica A., Foley R., Meltzer D.J., Nielsen R., Excoffier L., Mirazon Lahr M., Orlando
L., Willerslev E. Ancient genomes show social and reproductive behavior of early Upper Paleolithic foragers. // Science 03 Nov 2017: Vol. 358, Issue 6363, pp. 659-662. Smith et al., 2007. Smith, P., Muller, R., Gabet, Y. and Avishai, G., 2007. A computerized model for reconstruction of dental ontogeny: A new tool for studying evolutionary trends in the dentition. Springer Netherlands, Dordrecht, pp. 275288.

Sokal and Rohlf, 2012. Sokal, R., Rohlf, F., 2012. Biometry: The Principles and Practice of Statistics in Biological Research.4th Edition. 973 pages

Sulerzhitskiy et al., 2000, Sulerzhitskiy L.D., Petit P., Bader O.N. Radiouglerodniy vozrast poseleniya i obnaruzhennykh pogrebeniy, In: Homo Sungerensis, Verkhnepaleoliticheskiy chelovek: evolutsionnye i ekologicheskiye aspekty issledovaniya, Moscow, Nauchniy Mir, pp 30-34 Uldin, 2017. Uldin, T., 2017. Virtual anthropologya brief review of the literature and history of computed tomography. Forensic Sciences Research

Vasilyev, 2000. Vasilyev S.V., 2000, Craniotrigonometry of skulls from grave 2, In: Homo Sungerensis, Verkhnepaleoliticheskiy chelovek: evolutsionnye i ekologicheskiye aspekty issledovaniya, Moscow, Nauchniy Mir, pp 253-254

Vasilyev and Gerasimova, 2017. Vasilyev S.V., Gerasimova M.M. Historiographical review comprehensive study of the Upper Paleolithic site Sungir on the Klyazma river and its dwellers (brief archaeological and paleoanthropological overwiew) // le Sungirien. Edit. S. Vasilyev, A. Sinitsyn, M. Otte., Etudes et Recherches Archeologiques de lUniversite de Liege, Liege, 2017, Pp. 47-60.

Zubov, 2000. Zubov A.A,. 2000 Morfologicheskoe issledovanie detey iz sungirskogo pogrebeniya 2, In: Homo Sungerensis, Verkhnepaleoliticheskiy chelovek: evolutsionnye i ekologicheskiye aspekty issledovaniya, Moscow, Nauchniy Mir, pp 256270. 